FciDioc

\section{Allogeneic Adipose Mesenchymal Stem Cell Therapy in a Desperate Case of Forearm and Hand Ischemia}

\section{International Journal of Stem Cell Research and Transplantation (IJST) ISSN:2328-3548}

Riera del Moral L ${ }^{1,2,3^{*}}$, Salazar Álvarez $\mathrm{AE}^{2}$, Stefanov Kiuri $\mathrm{S}^{1,2}$, Martin Segarra $\mathrm{O}^{4}$, Luque $\mathrm{JM}^{4}$, Fernández $\mathrm{ME}^{5}$, García Arranz $\mathrm{M}^{3,6}$

${ }^{1}$ Department of Vascular Surgery, "Hospital Universitario La Paz”, Madrid. Spain.

${ }^{2}$ Department of Vascular Surgery, Hospital Quirón Ruber Juan Bravo, Madrid, Spain.

${ }^{3}$ Department of Surgery, Universidad Autónoma de Madrid, Madrid, Spain.

${ }^{4}$ Department of Internal Medicine, Hospital Quirón Ruber Juan Bravo, Madrid, Spain.

${ }^{5}$ HealthResearch Institute, Unit of Cell Therapy Research, "Hospital Universitario Gregorio Marañón”, Madrid, Spain.

${ }^{6}$ HealthResearch Institute, Unit of Cell Therapy Research, "Hospital Universitario Fundación Jiménez Díaz”, Madrid, Spain.

\title{
Abstract
}

Limb ischemia is a main health problem in a growing elderly population. Although there are more medical, surgical and endovascular approaches to this condition, it is not unusual to find patients with no options but major amputations. Here in we present one case of critical upper limb ischemia due to humeral thrombosis which was unsuccessfully treated by surgery that was referred to our center. We had the opportunity to offer an allogeneic stem cell treatment before doing a complete amputation of the limb. This treatment was given in a compassionate way, with agreement of the Spanish National Medical Agency. 70 million adipose mesenchymal stem cells were injected intramuscularly 7 days after admission. Two minor finger amputations were necessary in the immediate follow up period. One year after the procedure our patient is still doing well, without pain in his hand and returned to normal activities. Allogeneic stem cell treatment is a feasible treatment that can be offered in a short time from the index event and that might have a true potential for improving neo-vascularization in critically ischemic limbs. It might also be useful then as a co-adjuvant therapy in other revascularization treatments, including medical treatment alone.

Abbreviations: ASC: Adipose Tissue-Derived Stromal Cells; HHI: Hand/Hand Index; ABI: Ankle/Brachial Index; IFATS: International Federation for Adipose Therapeutics; ISCT: International Society for Cellular Therapy.

\section{Introduction}

Upper limb critical ischemia is usually due to complex autoimmune pathology or associate comorbidity and rarely to arteriosclerosis alone. It is not unusual to have no clear surgical options in this cases. Pharmacologic treatment based on vasodilators and anticoagulation alone or in combination with immune modulators tends to be the first option in these cases, but sometimes this is not enough [1]. There is a growing body of evidence regarding the possible benefits of regenerative medicine based on the use of stem cells $[3,4]$.

The use of adipose tissue-derived progenitors as a therapeutic has grown substantially in the past decade. Multiple laboratories have established a standardized method for isolation and preparation for implantation in a reproducible manner, as it can be found in some other papers. This process allows the emergence of an adherent cell population termed adipose tissue-derived stromal cells (ASC). ASCs are a heterogeneous population that includes multipotent cells with the ability to differentiate into adipocytes, chondrocytes, and osteoblasts, among other lineage pathways [5]. After obtaining a determinate amount of cells, these usually need to be cultured and expanded in order to obtain a more relevant number of them, because after their implantation in a damaged tissue approximately $40 \%$ won't be able to survive and interact as desired. In our previous experiences we have found that all this process of preparation, isolation and culture is neither as safe nor as quick as we usually need. Our patients with ischemia of the ex-

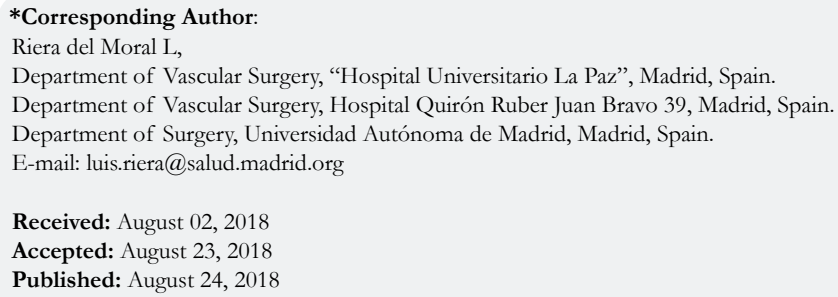

Copyright: Riera del Moral $\mathbf{L}^{\circ}$ 2018. This is an open-access article distributed under the terms of the Creative Commons Attribution License, which permits unrestricted use, distribution and reproduction in any medium, provided the original author and source are credited. 
tremities usually have many comorbidities and a severe affection of the limb that can `t wait one month or more to have a sufficient amount of cells to be treated.

In this particular scenario appears the possibility of using allogeneic cells, which can be previously isolated, prepared, cryopreserved and be available for treatment in a proper quantity between 4 and 6 days after the decision is made.

Adult mesenchymal stem cells, such as ASCs, are considered well tolerated, as demonstrated in their administration without human leukocyte antigens and without immunosuppression [6, 7]; Considering these studies they have been used in numerous clinical trials [8-10]. The proposed mode of action is based on the regulation of the immune system through two more or less known effects: on one hand a local anti-inflammatory, anti proliferative and tissue repair effect at the sites of inflammation; and on the other hand a systemic immunomodulatory effect mediated by the induction of regulatory $\mathrm{T}$ cells which suppress the autoreactive cells.

We report the case of a severe hand ischemia caused by thrombosis of ulnar and radial arteries probably secondary to a very complicated Rheumatoid Arthritis in which surgical treatment and pharmacologic fibrinolysis have previously failed.

\section{Case Report}

74-year-old male referred to our center with important pallor and cyanosis, coldness, swelling and severe pain of his left hand (Figure 1). He was affected by a complicated rheumatoid arthritis with Sjogren's Syndrome and importantly impaired by several articular pain and complications due to an intensive corticosteroid and immune modulating treatment (methotrexate). He was being treated for non-complicated hypertension with one drug. He is also a former smoker with diffuse arteriosclerosis and affection of the heart and legs with previous coronary artery disease and intermittent claudication. When he was younger he used to be a semi professional cyclist so even though now a days he lives an independent life he feels very physically limited which often leads him to depression.

Prior to our first assessment he was unsuccessfully treated with two failed patch angioplasties and thrombectomies. Finally he was offered a major transhumeral amputation. On physical examination there were no palpable pulses in the left arm. A recent surgical wound with stitches in the forearm showed no complications and the hand/hand index was 0.2. The hand/hand index (HHI) is an extrapolation of the well-known Ankle/Brachial index (ABI; normal range: 0.9-1.2).

We also measured the transcutaneous oxygen record in the affected hand using near infrared spectroscopy (INVOS Cerebral/Somatic Oximetry by Medtronic ${ }^{\mathrm{TM}}$ ) that was low (64\%) compared with the other hand $(73 \%)$. Oximetry measurement is a non-invasive diagnostic tool increasingly being used in clinical practice. Existing evidence suggests that reduction of oximetry records is correlated with an increase in skin ischaemia, and its measurement has been shown to have predictive value for wound healing in diabetic patients, success rate of hyperbaric oxygen therapy, amputation rate in patients suffering from peripheral vascular disease or with ischaemic ulcers [11].

Considering the autoimmune nature of the disease the Department of Internal Medicine was consulted. They performed all necessary tests to rule out autoimmune and hematologic diseases, finding negative IgG, IgM Cardiolipin and Beta 2 Glycoprotein antibodies. Under the diagnosis of antiphospholipid syndrome associated to rheumatoid arthritis we started the treatment with low molecular weight heparin at full dose, alprostadil, prednisone, pain relief with opioids and an axillary catheter to infuse local anesthesia near the brachial plexus.

Our group has an open line of research in stem cell therapy so when we were faced with the diagnosis of critical ischemia of the upper left limb secondary to probable autoimmune thrombosis with no response to surgical treatment we offered him a new therapy based on the adipose mesenchymal stem cells properties for neovascularization and immunomodulation.

The Spanish Medical Agency and the Local Institutional Board Committee authorized the compassionate use of the treatment and the patient gave his informed consent. We used previously isolated and frozen cells from a healthy donor in an authorized laboratory (AEMPS-20090211-TA). These cells were characterized according to the International Federation for Adipose Therapeutics (IFATS) and Science and the International Society for Cellular Therapy (ISCT) recommendations. They were unfrozen and passed twice, reaching the goal of 70 million within 7 days (1million/kg of patients weight, as we have previously done). Then, the patient was transferred to the surgical theater where we implanted the cells in 25 intramuscular aliquots of $1 \mathrm{ml}$ under regional anesthesia obtained through axillary catheter and mild sedation (Figure 2) in about 15 minutes of simple procedure.

Figure 1. Clinical aspect of the extremity on admission.

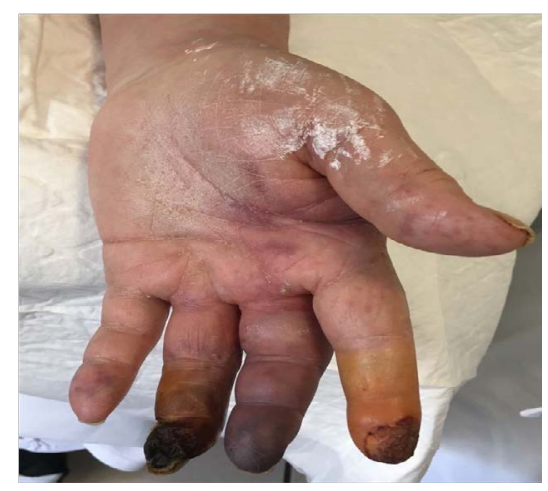


Two days after the procedure the patient experienced an important decrease in pain medication consume being discharged on the 7 th postoperative day with the necrotic areas of his fingers treated only with local iodine in order to see where the ischemia was going to delimitate. He continued treatment with aceno cumarol to achieve an INR of 2, aspirin (100mg daily), simvastatin (40mg daily) and anendothelin receptor antagonist (Bosentan, $62.5 \mathrm{mg} / 12 \mathrm{~h}$ ). Three weeks after discharge we decided to amputate the necrosed areas involving the first and second phalanges of the fingers with local anesthesia. Mobility was almost normal one month later, with mild claudication of the limb but with the ability to perform his normal activity. Three months later he restarted to do some exercise in a stationary bicycle. 6 months after the discharge he remains pulse less but asymptomatic and returned to his previous normal activity, including driving his car. The hemodynamic study revealed improvement in the Doppler signals with hand/hand index of 0.75 (Figure 3) and an increase in the Oximetry records (66\% vs $67 \%$ ).

Tissue perfusion was clinically improved by restoration of skin temperature, mobility, venous filling and necrosis healing. We performed a control CT scan that wasn't able to determine new vessel formation, but a new hemodynamic study confirmed this improvement, evidenced by the improvement of the hand/hand index greater than 0.15 (when you perform a revascularization treatment you can consider it a clinical success when you can detect an improvement equal or greater than 0.15 ).
We decided to maintain the treatment with antagonists of endothelin receptors (Bosentan 62.5mg/12h) for 12 months based on the safety and good results obtained by similar experiences in which they treated non-revascularizable patients with critical limb ischemia different to sclerodermia [12]. One year later, the patient is doing well with no claudication of the hand and has returned to his normal activities.

\section{Discussion}

Upper limb ischemia is usually a dramatic situation, especially when occurs in young, working people. We believe that this case was a rare but well known complication of the Rheumatoid Arthritis, which can provoke arterial thrombosis, specially in the forearms $[13,14]$. Since he had not too many cardiovascular risk factors the surgical failures gave us no doubts about the true origin of this case, an inflammatory disease. The desperate situation of the left hand in an active patient made us explore all the possibilities before an amputation.

Stem cell therapy is a new line of treatment that is winning adepts all across the world. It is a low hazard treatment which can result in the increase of arterial perfusion, reduce inflammation and resolve pain or difficulties in the healing processes [15-17]. Inflammatory diseases might have better response to stem cell therapy than arteriosclerosis alone, but they also tend to respond better to

Figure 2. Intramuscular injection of ASC.

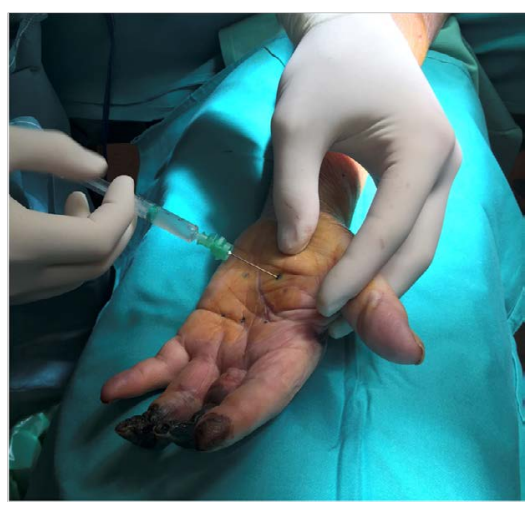

Figure 3. Functional recovery 12 months after the procedure.

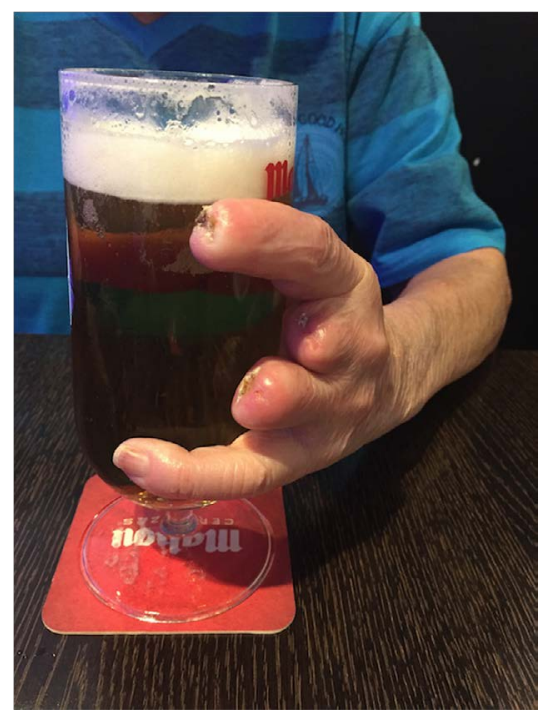


medical treatment.

We consider the intramuscular implantation of the cells to be better than the intra-arterial injection because: i) we believe that the most important effect of this therapy is the local stimuli, ii) it permits a broader spread of the treatment through the extremity and iii) we didn't have a clear proximal artery to use. The total duration of the process of the injection of the cells was really short and simple.

The exact mechanism of improved perfusion isn't well known, but secretion of large amount of cytokines like endothelial growing factor on ischemic conditions, the vasculogenesis promoted by endothelial progenitor cells and the anti-inflammatory and immune modulating properties of these cells [18] might be responsible for the clinical response [19]. These different factors might explain the early relieve of pain and the improvement of vascularization at medium and large term [20]. Adipose mesenchymal cells have de advantage of being easy to obtain with low risks for the patient [21-23], but there is still a lot of room to improve when we talk about severe ill patients with lots of comorbidities, as it uses to be in Vascular Surgery field.

This patient experienced a durable improvement of the ischemic pain, motor impairment and healing of the minor amputations with this new approach. We believe that the multilevel action of this therapy might have a role in future treatment strategies, especially in those of small vessel pathology or inflammatory diseases of the upper extremities, but much more investigation is needed to access the real utility of this line of treatment.

\section{References}

[1]. Comerota AJ, Link A, Douville J, Burchardt ER. Upper extremity ischemia treated with tissue repair cells from adult bone marrow. J Vasc Surg. 2010 Sep;52(3):723-9. doi: 10.1016/j.jvs.2010.04.020. PubMed PMID: 20576396.

[2]. Koshikawa M, Shimodaira S, Yoshioka T, Kasai H, Watanabe N, Wada Y, et al. Therapeutic angiogenesis by bone marrow implantation for critical hand ischemia in patients with peripheral arterial disease: a pilot study. Curr Med Res Opin. 2006 Apr;22(4):793-8. PubMed PMID: 16684440.

[3]. Sprengers RW, Moll FL, Verhaar MC. Stem cell therapy in PAD. Eur J Vasc Endovasc Surg. 2010 Mar;39 Suppl 1:S38-43. doi: 10.1016/j. ejvs.2009.12.001. PubMed PMID: 20153223.

[4]. Riera del Moral L, Salazar Álvarez A, Stefanov Kiuri S, Tong H, Riera de Cubas L, García-Olmo D, et al. Phase Ib Open Clinical Trial to Assess the Safety of Autologous Mesenchymal Stem Cells for the Treatment of Nonrevascularizable Critical Lower Limb Ischemia. J Stem Cell Res Ther. 2017;7(6):391-398.

[5]. Bourin P, Bunnell BA, Casteilla L, Dominici M, Katz AJ, March KL, et al. Stromal cells from the adipose tissue-derived stromal vascular fraction and culture expanded adipose tissue-derived stromal/stem cells: a joint statement of the International Federation for Adipose Therapeutics and Science (IFATS) and the International Society for Cellular Therapy (ISCT). Cytotherapy. 2013 Jun;15(6):641-8. doi: 10.1016/j.jcyt.2013.02.006. PubMed PMID: 23570660.

[6]. Uccelli A, Moretta L, Pistoia V. Immunoregulatory function of mesenchymal stem cells. Eur J Immunol. 2006 Oct;36(10):2566-73. PubMed PMID: 17013987.

[7]. Zhang J, Huang X, Wang H, Liu X, Zhang T, Wang Y, et al. The challenges and promises of allogeneic mesenchymal stem cells for use as a cell-based therapy. Stem Cell Res Ther. 2015 Dec 1;6:234. doi: 10.1186/s13287-0150240-9. PubMed PMID: 26620426.

[8]. Griffin MD, Ritter T, Mahon BP. Immunological aspects of allogeneic mesenchymal stem cell therapies. Hum Gene Ther. 2010 Dec;21(12):1641-55. doi: 10.1089/hum.2010.156. PubMed PMID: 20718666.
[9]. Munir H, McGettrick HM. Mesenchymal stem cell therapy for autoimmune disease: risks and rewards. Stem Cells Dev. 2015 Sep 15;24(18):2091100. doi: 10.1089/scd.2015.0008. PubMed PMID: 26068030

[10]. Panés J, García-Olmo D, Van Assche G, Colombel JF, Reinisch W, Baumgart DC, et al. Expanded allogeneic adipose-derived mesenchymal stem cells (Cx601) for complex perianal fistulas in Crohn's disease: a phase 3 randomised, double-blind controlled trial. Lancet. $2016 \mathrm{Sep}$ 24;388(10051):1281-90. doi: 10.1016/S0140-6736(16)31203-X. PubMed PMID: 27477896.

[11]. Yip WL. Evaluation of the clinimetrics of transcutaneous oxygen measurement and its application in wound care. Int Wound J. 2015 Dec;12(6):6259. doi: 10.1111/iwj.12356. PubMed PMID: 25196124.

[12]. Conejero AM, Méndez MM, Sánchez SG, López IM, Horcajo RR, Hernando FS. Effect of Bosentan in Patients with digital ulcers of ischemic etiology. Angiology. 2011 Jan 1; 63 (1): 7-10.

[13]. Hintenberger R, Falkinger A, Danninger K, Pieringer H. Cardiovascular disease in patients with autoinflammatory syndromes. Rheumatol Int. 2018 Jan;38(1):37-50. doi: 10.1007/s00296-017-3854-7. PubMed PMID: 29094181.

[14]. Kim KJ, Baek IW, Park KS, Kim WU, Cho CS. Association between antiphospholipid antibodies and arterial thrombosis in patients with rheumatoid arthritis. Lupus. 2017 Jan;26(1):88-94. PubMed PMID: 27510601.

[15]. Zuk PA, Zhu MI, Mizuno H, Huang J, Futrell JW, Katz AJ, et al. Multilineage cells from human adipose tissue: implications for cell-based therapies. Tissue Eng. 2001 Apr;7(2):211-28. PubMed PMID: 11304456.

[16]. García-Olmo D, García-Arranz M, García LG, Cuellar ES, Blanco IF, Prianes LA, et al. Autologous stem cell transplantation for treatment of rectovaginal fistula in perianal Crohn's disease: a new cell-based therapy. Int J Colorectal Dis. 2003 Sep;18(5):451-4. PubMed PMID: 12756590.

[17]. Lawall H, Bramlage P, Amann B. Treatment of peripheral arterial disease using stem and progenitor cell therapy. J Vasc Surg. 2011 Feb;53(2):445-53. doi: 10.1016/j.jvs.2010.08.060. PubMed PMID: 21030198.

[18]. Koenen P, Spanholtz TA, Maegele M, Stürmer E, Brockamp T, Neugebauer $\mathrm{E}$, et al. Acute and chronic wound fluids inversely influence adipose-derived stem cell function: molecular insights into impaired wound healing. Int Wound J. 2015 Feb;12(1):10-6. doi: 10.1111/iwj.12039. PubMed PMID: 23490259.

[19]. McIntosh KR, Frazier T, Rowan BG, Gimble JM. Evolution and future prospects of adipose-derived immunomodulatory cell therapeutics. Expert Rev Clin Immunol. 2013 Feb;9(2):175-84. doi: 10.1586/eci.12.96. PubMed PMID: 23390948.

[20]. Salazar Alvarez AE, Garcia Arranz M, Riera Del Moral L, Mendieta Azcona C, Leblic Ramirez I, Fernandez Heredero A. Adipose mesenchymal stromal cell therapy in a desperate case of right-hand ischemia. Cytotherapy. 2016 Jun;18(6):725-8. doi: 10.1016/j.jcyt.2016.03.297. PubMed PMID: 27173748.

[21]. García-Olmo D, García-Arranz M, Herreros D, Pascual I, Peiro C, Rodríguez-Montes JA. A phase I clinical trial of the treatment of Crohn's fistula by adipose mesenchymal stem cell transplantation. Dis Colon Rectum. 2005 Jul;48(7):1416-23. PubMed PMID: 15933795.

[22]. Álvarez PD, Garcia-Arranz M, Georgiev-Hristov T, Garcia-Olmo D. A new bronchoscopic treatment of tracheomediastinal fistula using autologous adipose-derived stem cells. Thorax. 2008 Apr;63(4):374-6. doi: 10.1136/ thx.2007.083857. PubMed PMID: 18364447.

[23]. Roubelakis MG, Trohatou O, Roubelakis A, Mili E, Kalaitzopoulos I, Papazoglou G, et al. Platelet-rich plasma (PRP) promotes fetal mesenchymal stem/stromal cell migration and wound healing process. Stem Cell Rev. 2014 Jun;10(3):417-28. doi: 10.1007/s12015-013-9494-8. PubMed PMID: 24500853.

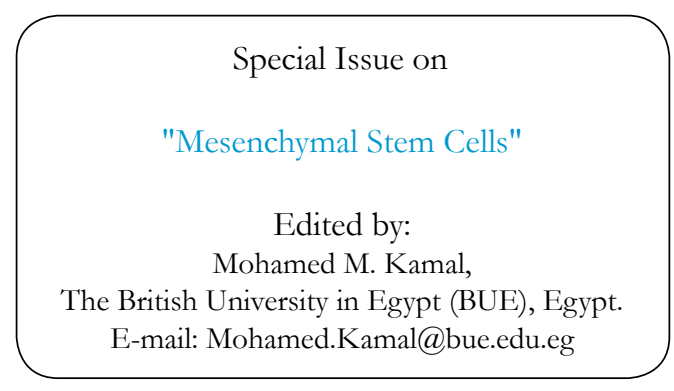

